\title{
Thermal Study of Flapping Jet by Infrared Thermography
}

by J.-M. Buchlin, I.A. Horvath, R. Herrero and Ph. Planquart

von Karman Institute for Fluid Dynamics

Chaussée de Waterloo, 72. B-1640 Rhode-Saint-Genèse (Belgium)

\section{Abstact}

The paper describes an experimental investigation of convective heat transfer in case of planar air jet impinging a hot V-shaped surface. In such a flow configuration the jet experiences a flapping behaviour leading to a stable self-sustained periodic flow characterized by a constant Strouhal number. To determine the timedependent mapping of the convective heat transfer coefficient infrared thermography is used in connection with a very thin metallic-foil of low heat capacity for the test surface, which is heated by Joule effect. The effect of the crucial parameters on heat transfer is analyzed.

\section{Introduction}

Due to their ability to produce high local transport coefficients, impinging jets are currently involved in many industrial and engineering processes where heat or mass transfer prevails. Jet arrays of various sizes and geometrical arrangements are found in industrial applications, which range from spot cooling of electrical components to the heat treating of large metallic sheets. To mention some further applications:

- Design of anti-icing system of a wing

- Annealing of metal and plastic belts

- $\quad$ Drying of paper and textiles

- Cooling of turbine blades...

The relatively large heat transfer rates obtained with impinging streams, compared with classical boundary layer flows explain the popularity of this technique. In addition, impingement is often attractive for the designer, who can in this way control easily the area and the distribution of the heat transfer. In this view, the case of flapping jet, which increases the span of the affected cooling (or heating) area takes a peculiar importance. Therefore, the flapping behaviour of a jet has a wide prospect and deserves to be investigated.

The objective of the study is to determine experimentally the convective heat transfer mapping at the impact of an oscillating jet impinging on a concave surface and to assess the applicability of infrared thermography to retrieve the time-dependent variation of heat exchange during this cyclic motion. The V-shaped plate has been selected for this investigation because it has been proved in literature that such geometry induces readily a periodic flapping motion of an impinging planar jet [1-2].

\section{Experimental facility}

A schematic of the experimental test set-up is proposed in figure 1. It consists of the V-shaped surface composed of two plates in wood forming an angle of $90^{\circ}$. Figure 2 shows that the upper plate includes a very thin metallic-foil of low heat capacity for the test surface, which is heated by Joule effect. This heated foil is an inconel split of $0.290 \mathrm{~m}$ long, $0.145 \mathrm{~m}$ wide and $20 \mu \mathrm{m}$ thick. It is connected to a power supply instrumented with a voltmeter and an ammeter. The heat flux may be adjusted from $1000 \mathrm{~W} / \mathrm{m}^{2}$ to $3000 \mathrm{~W} / \mathrm{m}^{2}$. Similar idea has been developed with success to study time-space characteristics of heat transfer in turbulent boundary layer [3].

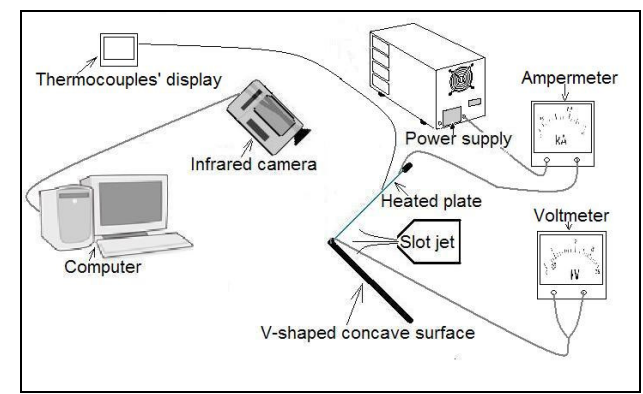

Fig. 1. Schematic of the test setup

The jet is obtained by flowing dry compressed air through a slot nozzle, the hydraulic diameter of which is $D_{h}=7.9 \mathrm{~mm}$. The jet is oriented horizontally and impinges on the internal apex of the $V$ shaped corner. The nozzle standoff distance, $\mathrm{L}$, from the corner is varied from $0.08 \mathrm{~m}$ to $0.125 \mathrm{~m}$.

Prior to the IR measurements, the velocity of the slot-jet was calibrated versus the pressure of the stagnation chamber of the nozzle by means of Pitot tube and pressure transducers. The exit jet velocity, $U$, is ranging from $4 \mathrm{~m} / \mathrm{s}$ to $12 \mathrm{~m} / \mathrm{s}$. 

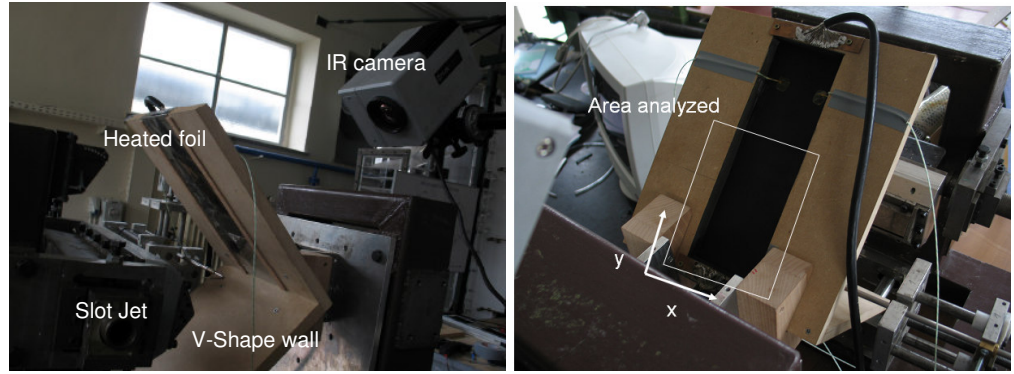

Fig. 2. Views of the test setup

The Infrared radiometer is a Thermocam SC3000 with a NETD of about $0.03{ }^{\circ} \mathrm{C}$ at a wall temperature of $30^{\circ} \mathrm{C}$. The camera is approximately located half a meter from the upper convex side of the V-shaped surface, and it is perpendicular to the external side of the heated plate coated with high-emissivity paint $(\varepsilon \approx 0.96)$. This camera is connected to a computer monitored by theThermoCAM Researcher 2001 program. The common procedure followed is to record Object Signal (OS) from the IR camera and to apply VKI in-house DIP software. As a consequence IR radiometer calibration is requested via thermocouples flush-mounted on the heated foil. Typical calibration curve is plotted in figure 3 .

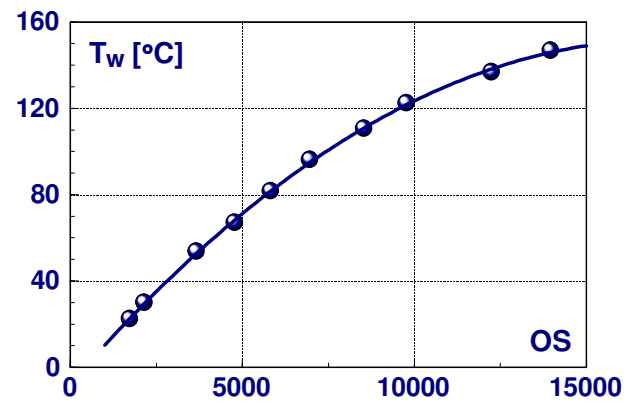

Fig. 3. Infrared radiometer calibration

\section{Flapping phenomenon}

Flapping phenomenon is a self sustained oscillation due to geometrical constraints and/or unstable boundary conditions. In the present investigation the $\mathrm{V}$-shaped surface proves to be a sufficiently strong actuator to induce a clear periodic flapping motion of the jet with a constant frequency, $f$.

A campaign of tests has been dedicated to the determination of the flapping frequency of the jet. Hot wire at constant temperature was placed on the axis of the jet at mid distance between the nozzle and the apex of the corner. The FFT of the output signal of the hot wire yields the flapping frequency of the jet, which appears as a noticeable peak in the power spectrum. The results are expressed in terms of the dimensionless Stanton number $\mathrm{St}=\mathrm{f} . \mathrm{L} / \mathrm{U}$ and the normalised standoff distance $\mathrm{L} / \mathrm{D}_{\mathrm{h}}$. Figure 4 shows that the Stanton number is constant in the range of the Reynolds number, $\mathrm{Re}=U . \mathrm{D}_{\mathrm{h}} / \mathrm{v}$, tested. Such a finding, which is in full agreement with the data reported in [1-2], indicates that the flapping frequency increases linearly with the exit velocity of the jet in case of a given standoff distance.

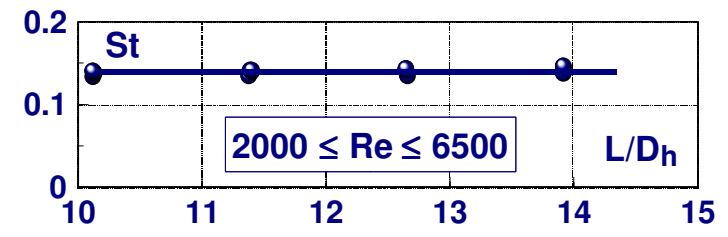

Fig. 4. Flapping Stanton number

\section{Thermal results}

The planar configuration of the jet leads to a temperature mapping exhibiting a one dimensional character as observed on the false-colour thermograph displayed in figure 5 . Therefore only heat transfer variations in time and along the longitudinal axis Oy are retained. 


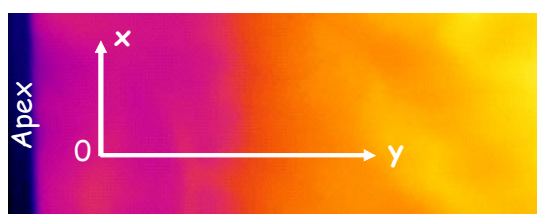

Fig. 5. IR thermograph

Scanning the heated flat plate without jet, situation of pure radiation and natural convection where the global heat transfer coefficient is practically constant, points out the very good uniform heating of the whole span of the inconel foil.

In presence of jet, the local convective heat transfer coefficient is inferred from the temperature of the wall $\mathrm{Tw}(\mathrm{y})$ by application of the Newton law:

$$
h_{y}=\frac{q_{c v}}{T_{w}(y)-T_{j}}
$$

The temperature distribution $T_{w}(y)$ measured by the IR camera is assumed to be representative of the surface side washed by the jet owing to the very small thickness and consequently the very low value of the Biot number of the heated foil $(B i<0.001)$. $T_{j}$ is the temperature of the jet at the exit of the nozzle while $q_{c v}$ is the actual heat flux removed by convection. It is obtained by subtracting the conduction, natural convection and radiation contribution from the Joule heating [4-6]; it turns out that In such a thin-foil design, the thermal losses by conduction are negligible $(\leq 1 \%)$, while the heat loss by radiation and natural convection does not exceed $5 \%$ of the total flux.

The flapping behaviour of the jet results in a change in time of the convective heat transfer. This modification is captured by the IR camera in terms of local wall temperature fluctuations, which are typically characterised by mean amplitude ranging from 1 to $4^{\circ} \mathrm{C}$ while the mean wall temperature is ranging from $50^{\circ} \mathrm{C}$ to $100^{\circ} \mathrm{C}$ depending on jet velocity and heat flux. As a result of data processing, figure 6 shows illustrative time variations of local convective heat transfer. Such results are proving that the present IR thermography technique is efficiently able to capture the trace of the sweeping jet.

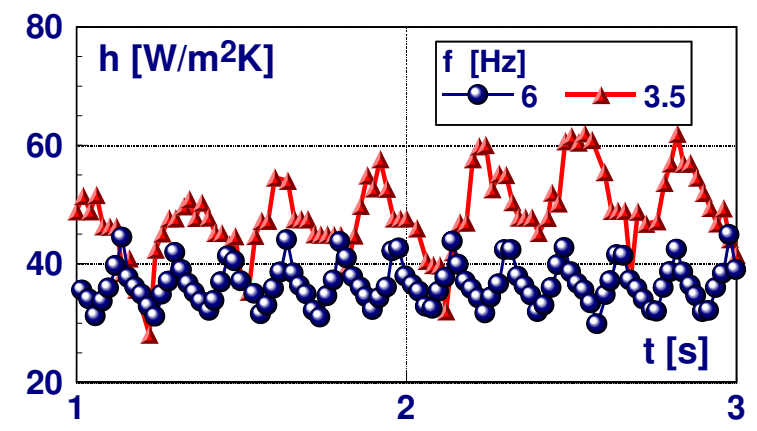

Fig. 6. Time variation of local heat transfer coefficient

As usual the heat transfer data are represented in terms of the dimensionless Nusselt number.

$\mathrm{Nu}_{\mathrm{y}}(t)=\frac{h_{y}(t) \cdot D_{h}}{k_{f}}$

where $k_{f}$ is the thermal conductivity of the fluid. Plots such as those displayed in figure 6 allow the determination of the local time-averaged Nusselt number, $<\mathrm{Nu}>$, the typical longitudinal distribution of which is shown in figure 7 for a normalised standoff distance of 15.8 and Reynolds number ranging from 3160 to 7370 . Time-averaged heat transfer augments as the jet Reynolds number increases and the highest value is found in the apex area. Such behaviour looks similar to that of impinging jet on a flat plate. However in the case flapping jet a rough-shape of plateau seems to be looming before the usual decline of heat transfer downstream. 


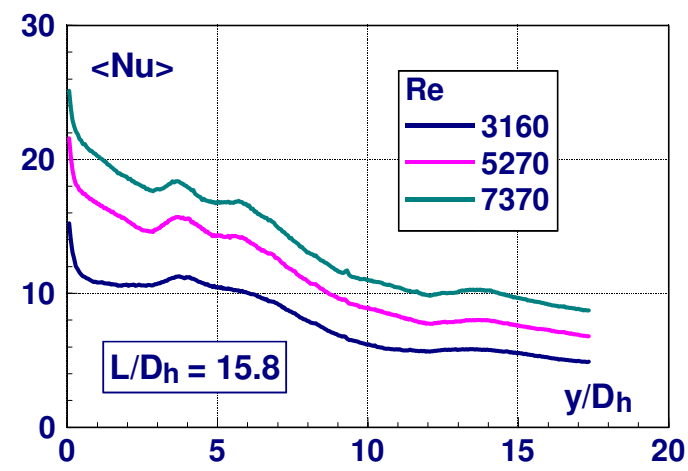

Fig. 7. Nusselt number distribution

The normalised local time-averaged Nusselt number, $<\mathrm{Nu}>/<\mathrm{Nu}>\max$, measured at $\mathrm{y} / \mathrm{Dh}=5.7$ is plotted versus the dimensionless standoff distance for Reynolds number ranging from 2113 to 6340 in figure 8 . <Nu> experiences a decrease of about $13 \%$ as the standoff distances nozzle increases by $50 \%$.

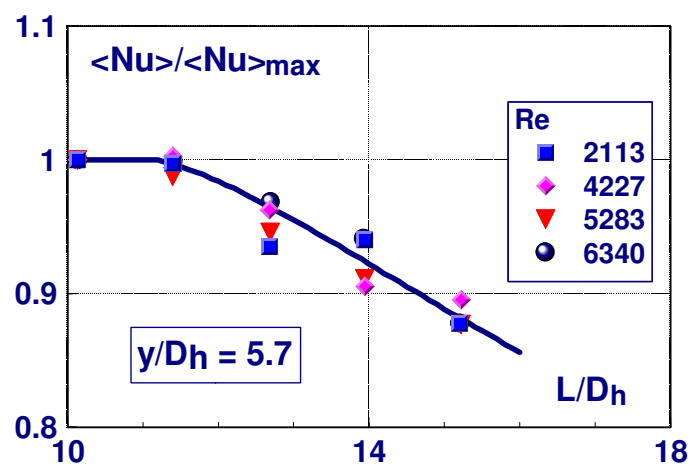

Fig. 8. Local normalised Nusselt-number versus the normalised standoff distance

Impinging jet heat transfer data for $V$-shaped and flat plates are compared in figure 9 for same Reynolds and apex standoff distance. As anticipated V-shaped configuration leads to higher heat exchange performance mainly due to the periodic flow behaviour and reduction of the effective standoff distance when the jet is sweeping.

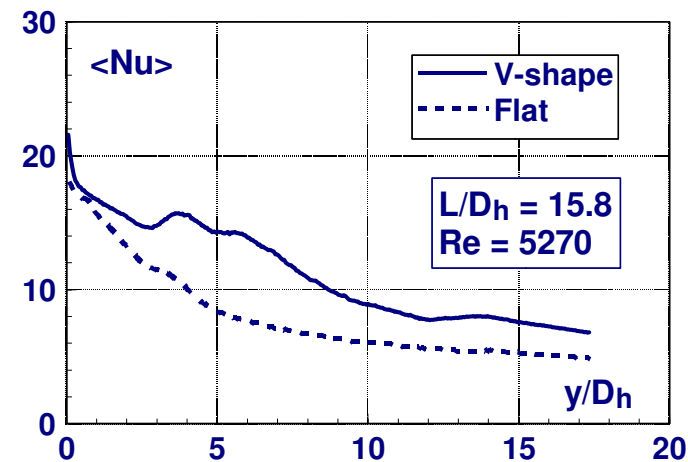

Fig. 9. V-Shaped-flat plate comparison

\section{Conclusion}

An experimental investigation of convective heat transfer in case of planar air jet impinging a hot V-shaped surface is presented. Such a configuration leads to a stable self-sustained periodic flow of flapping jet characterized by a constant Strouhal number

This flapping phenomenon is captured by application of infrared thermography associated with very thin heated foil.

The sweep of jet due to flapping results in a larger effective heat transfer area and higher convective heat transfer coefficients compared to flat plate. 


\section{REFERENCES}

[1] Cheng-Kuang Lin, Fei-Bin Hsiao and Shyh-Shiun Sheu, Flapping motion of a Planar Jet Impinging on a Vshaped Plate, Journal of Aircraft, vol.30 no.3 (320-325),1993.

[2] Gwo-Bin Lee, Tzu-Ying Kuo and Wan-Yu Wu, A novel micromachined flow sensor using periodic flapping motion of a planar jet impinging on a V-shaped plate, Experimental Thermal and Fluid Sciences, vol 26, pp 435-444, 2002.

[3] Nakamura $\mathrm{H}$, and Igarashi T, A new technique for measurements of unsteady heat transfer to air using a thin metallic-foil and infrared thermography, International Heat Transfer Conference 13, Sydney,Australia, August 2006.

[4] Buchlin J.-151M and Dubois M, Heat transfer of impinging multijet system. An application of the quantitative thermography. QIRT 1992, EUROTHERM Seminar 27, Châtenay-Malabry, France, July 7-9, 1992.

[5] Buchlin J.-M, Gouriet j.-B, * van Beeck, J and Renard M, Infrared Thermography Study of Heat Transfer in an Array of Slot Jets, QIRT2002, Collegium Ragusinum, Dubrovnik, Croatie

[6] Buchlin J.-M, Le transfert de chaleur convectif et la thermographie infrarouge , 1ère Conférence internationale sur la conversion et la maîtrise de l'énergie, Sousse, Tunisie, 10-12 avril 2008. 
http://dx.doi.org/10.21611/qirt.2008.07_04_11 